\title{
Determining the Extent to Which Program Structure Features and Integration Mechanisms Facilitate or Impede Doctoral Student Persistence in Mathematics
}

\author{
Sarah Earl-Novell \\ Center for Studies in Higher Education, \\ University of California, Berkeley, Berkeley, CA, USA
}

\author{
snovell@berkeley.edu
}

\begin{abstract}
The primary concern of this paper is to determine the extent to which program structure features and integration mechanisms facilitate or impede doctoral student persistence. Program structure features comprise Ph.D. requirements in the form of a written preliminary examination and an oral qualifying examination. In addition, integration mechanisms relate to type of financial support, teaching opportunities, and advisor-advisee relationship. Twenty doctoral students enrolled in the mathematics doctoral program at the University of California Berkeley were interviewed regarding their perception of the key factors outlined above. This study relates to research suggesting the greater the extent to which students are integrated into the academic and social life of an institution, the more likely doctoral persistence (Lovitts, 2001; Tinto, 1993).
\end{abstract}

Key words: doctorate, integration, persistence, Ph.D., withdrawal.

\section{Introduction}

Mathematics, as a discipline, is faced with a number of concerns. Over the last twenty years, academic commentators have voiced disquiet over, 'the supply, quality, and composition of the U.S. talent pool in scientific and mathematics fields' (Stage \& Maple, 1996, p. 24). A recent survey indicates that throughout the 90s the number of full-time mathematics doctoral students decreased and looks set to continue declining albeit at a slower rate (American Mathematical Society [AMS], 2003). In addition, women and some ethnic minority groups remain under-represented at doctoral level (Herzig, 2002), despite initiatives and resources aimed at recruiting minorities into mathematics. Moreover, the number of doctorates awarded to U.S. citizens is declining (Herzig, 2002). Finally, studies show that as many as fifty percent of all doctoral students depart from their

Material published as part of this journal, either on-line or in print, is copyrighted by the Informing Science Institute. Permission to make digital or paper copy of part or all of these works for personal or classroom use is granted without fee provided that the copies are not made or distributed for profit or commercial advantage AND that copies 1) bear this notice in full and 2) give the full citation on the first page. It is permissible to abstract these works so long as credit is given. To copy in all other cases or to republish or to post on a server or to redistribute to lists requires specific permission and payment of a fee. Contact Publisher@InformingScience.org to request redistribution permission. studies (Lovitts, 2001) and mathematics is no exception; attrition rate estimates vary from $30 \%$ to $70 \%$ (Bowen \& Rudenstine, 2002).

Attrition is not only a cause for concern in terms of faculty time expended, institutional costs and public resource investment (MLA Committee, 1998), but the individual cost to the student is staggering in terms of 
financial, personal and professional consequences (Lovitts, 2001). Past research has identified a constellation of factors leading to attrition and, while the following section outlines a number of these factors, it is by no means exhaustive. Some faculty and administrators view doctoral departure as a function of the idiosyncrasies of individual students, such as lack of academic ability, motivation, or commitment. This discourse tends to place responsibility on the shoulders of the student, the so-called 'drop-out'. Yet research indicates that students who withdraw from their doctoral studies and students who persist share a similar grade point average (Lovitts, 2001). In addition, evidence suggests that several pre-entry factors are associated with high attrition such as delayed entrance into a doctoral program, a change of institution and/or discipline of study (Baird, 1993). Other external factors that may impede Ph.D. completion include marriage, having children or caring for elderly parents (Lovitts, 2001).

Nonetheless, there are those who argue that the rationale underpinning student departure is partly a function of what occurs post entry to a graduate program (Tinto, 1987) and, as such, high attrition cannot be understood independent of institution context. It is suggested, for instance, that the greater the extent to which students are integrated into the academic and social life of an institution, the more likely doctoral persistence (Lovitts, 2001; Tinto, 1993). As such, there are a number of mechanisms that serve to facilitate integration into a department such as availability of office space, effective mentoring schemes, type of financial support, teaching opportunities, and a good working relationship with advisor (Golde, 2000; Herzig, 2002). In addition, department features such program structure may also assist participation in the social and professional life of the department.

\section{Program Structure Features: the Preliminary and Qualifying Examinations}

A mathematics doctoral program in the U.S. takes the form of two stages. The first stage typically extends over a period of about three years and involves the student taking a number of courses culminating at the University of California with the sitting of a preliminary examination. The preliminary examination is a six hour written examination predominantly covering undergraduate material (UC Berkeley Mathematics website, 2004). The examination is sat before the start of each semester and doctoral students are required to pass it within their first three semesters of entering the mathematics program.

The second stage of the doctoral program commences with the qualifying examination which is a three hour oral examination that places emphasis on the students' area of specialization (UC Berkeley Mathematics website, 2004) and this must be attempted within the first two years of entry. As part of the latter process, students are required to find a prospective advisor who agrees to supervise the dissertation if the examination is successful. Once the preliminary and qualifying examinations have been successfully sat, the student moves onto identifying and working on a specific research area. In this latter stage, the advisor-advisee relationship is crucial since the doctoral student's primary contact is their advisor. There are few colleagues and peers with whom to collaborate due to the highly specialized nature of mathematics research.

\section{Integration Mechanisms}

Research on the relationship between type of funding and doctoral persistence is a largely contested area. Studies indicate that self-financing doctoral students are less likely to complete their graduate studies than students who receive funding irrespective of type (Lovitts \& Nelson, 2000; Pyke \& Sheridan, 1993). Whilst research shows that students with teaching assistantships, as opposed to students receiving fellowships, are less likely to complete their Ph.D.s (in Economics, English, Mathematics and Physics) (Ehrenberg \& Mavros 1995), a study conducted by Lovitts 
(2001) suggests that full-fellowship recipients are more at risk of non-completion than their funded counterparts. Despite financial support, they are less likely to be given office space and have limited contact with their peers often resulting in feelings of isolation and abandonment. This is a cause for concern given that students with minority status are most likely to receive fullfellowship support.

In relation to integration in a department, self-financing students typically display low levels of participation in the social and professional life of the department (Lovitts \& Nelson, 2000). Their funded counterparts (comprising teaching assistants, research assistants, and fellowship recipients) are more likely, however, to be integrated in the department academically as a result of close links with faculty (Pyke \& Sheridan, 1993). In agreement, Ethington and Pisani (1993) suggest that the assistantship, be it research or teaching, plays a fundamental role in social and academic integration working to socialize students into the academic community.

With regard to time-to-completion, Abedi and Benkin (1987) found that, on average, selffinancing students took two years longer to complete their doctoral studies than those whose income was from other sources. In addition, some evidence suggests that grant and fellowship recipients take longer to complete their studies compared to research or teaching assistants (Sheridan \& Pyke, 1994). Conversely, other studies show that fellowships lead to shorter completion times, whilst personal financing, research or teaching assistants increase completion time (Tuckman, Coyle, \& Bae, 1990).

A fundamental way in which doctoral students become integrated into a department is via faculty, especially advisor relationships. Faculty act as role models and are the mechanism through which primary socialization takes place (Girves \& Wemmerus, 1988, cited in Herzig, 2002). As Lovitt's explains,

"The advisor influences how the student comes to understand the discipline and the roles and responsibilities of academic professionals, their socialization as a teacher and researcher, the selection of a dissertation topic, the quality of the dissertation, and subsequent job placement" (2001, p. 131).

Furthermore, research suggests that close professional relationships are more likely to form with faculty of same sex (Berg \& Ferber, 1983) and, consequently, the under-representation of women faculty is detrimental to students in terms of a lack of role models.

\section{Analytic Strategy}

The primary concern of this paper is to determine the extent to which program structure features and integration mechanisms facilitate or impede doctoral student persistence. Program structure features comprise Ph.D. requirements in the form of a written preliminary examination and an oral qualifying examination. In addition, integration mechanisms relate to type of financial support, teaching opportunities, and advisor-advisee relationship. Twenty doctoral students enrolled in the mathematics doctoral program at the University of California Berkeley were interviewed regarding their perception of the key factors outlined above.

\section{Method}

The department was an interesting case study site given its first rate national ranking. In addition, the graduate program was both competitive and prestigious, and, with seventy faculty members, was reputable for representing most of the major fields in mathematics. A list of students' names was provided by the mathematics department and the sample selected by knocking on doors and 
asking graduates to participate in the study. With the exception of two students, both in the leadup to their qualifying examination, all students asked agreed to be interviewed.

Of those students interviewed, four were women and sixteen were men although it should be noted that women actually constitute nearly a third of doctoral recipients nationally (AMS, 2003). Despite this, other research conducted at the University of California Berkeley found that women constituted one fifth of those completing mathematics doctorates (Linn \& Kessel, 1996). Whilst the majority of students interviewed were U.S. citizens, six students were international (three students were from China and the remaining were from Romania, Brazil and Canada). A recent survey indicates that in 2001-2002 students with U.S. citizenship comprised 44\% of new doctoral recipients (AMS, 2003). All international students were male. Fifteen interviewees were Caucasian, four were Asian and one was African-American. With the exception of one math graduate aged 45 , the remaining interviewees were in their 20 s with a mode age of 26 . Five graduates were married and only one had dependents. This is in line with the dominant conceptualization of the student as 'an individual with few dependents and family responsibilities' (Pyke, 1997, p. 158).

In relation to year of study, half the sample was in their first to third year of study whilst the remaining half was in their fourth or fifth year. Fifteen of the participants interviewed had passed their qualifying exam. Although graduates in their sixth year of study are not uncommon, none were interviewed here. With regard to undergraduate institutions, the interviewees attended a variety of universities; ten interviewees attended private non-profit universities prior to their graduate studies (two of these graduates attended technical institutes, one attended an HBCU [Historically Black Colleges and Universities], and two attended ivy-league universities). Three interviewees attended public universities and the remaining seven graduates attended various international universities. Seventeen participants had completed an undergraduate degree in mathematics and the same number did not have a Masters degree.

The interviews were guided by a semi-structured questionnaire and each interview was recorded and transcribed. Interviews were between thirty minutes to one hour and thirty minutes in length. The quotes selected from the interview data were chosen because they crystallize certain themes. In some cases, however, quotes pertain to individual accounts and this is indicated throughout. All interviewees were guaranteed anonymity and confidentiality and, therefore, only gender and citizenship (domestic or international) are provided as identifier information in the following write-up.

\section{Results}

The findings are divided into two sections. The first section presents interview data relating to program structure features (comprising Ph.D. requirements in the form of a written preliminary examination and an oral qualifying examination). The second section details various integration mechanisms (including type of financial support, teaching experience, advisor-advisee relationship).

\section{Section 1: Program Structure Features}

\section{The preliminary examination}

Just over half the participants interviewed passed the preliminary examination on their first attempt. Whilst a small minority claimed it was 'easy', a more typical response was that it required a great deal of preparation and was difficult. Despite this, passing the preliminary examination provided a much-needed confidence boost: 
"I took it straight away and passed. I studied for it for quite a while. When I first saw the prelim I thought it was really hard but after practicing for a while, it was okay" (male, international doctoral student: 4).

"I spent a lot of time before preparing for the prelim but I passed and it gave me a lot of confidence" (male, domestic doctoral student: 8).

Two participants passed the preliminary exam on their third attempt and an additional student was due to take the exam a third time. In order to meet UC Berkeley's Ph.D. requirements in mathematics, doctoral students must pass the preliminary examination within their first three semesters. The pressure felt by these graduates was intense as indicated by the excerpts below:

"When I passed the prelim it was the third time and I got exactly the passing score. I attended workshops for the prelim the summer before. I passed the third time. It set me behind because I was studying for the prelim when people were hoping I would be studying for the qualifier, and I was studying for the qualifier when I was hoping to be doing my research and so when I was passed the qualifier I felt, and my advisor felt, I was a year behind" (male, domestic doctoral student: 4).

"So, I failed the first two times and I passed the third. I was really stressed out. But it worked out fine. I really, really worked hard on them" (female, domestic doctoral student: 2).

\section{The qualifying examination}

Fifteen of the participants interviewed had passed their qualifying exam. When asked the rationale underpinning the qualifying examination, a substantial number of doctoral students claimed that it provided them with an opportunity to demonstrate to examiners competence, a breadth and depth of knowledge, an ability to think independently and critically, and an ability to engage in articulate dialogue. Fairly typical were the following responses:

"In my opinion, they [the examiners] want to figure out whether you can think on your own which I guess is the criteria for a successful Ph.D. in mathematics. It's not so much about the material. The way I understood it...it's the way you deal with questions when you're stuck. It's the ideas you have" (male, domestic doctoral student: 6).

"We speculate a lot about that [the rationale of the qualifying examination] in the department. It seems like it's almost a formality now as so many people pass. I think it's primarily designed to show that you can have a dialogue in your chosen area and you can have a back and forth discussion. And they [the examiners] find out not so much what you know but just how well you can interact with other mathematicians and just how well you can use what you do know to help you figure out problems" (male, domestic doctoral student: 3 ).

Two participants stated that the qualifying examination was useful as part of the process comprised selecting faculty to sit on an examination committee, one of whom would then act as dissertation advisor throughout the remainder of the Ph.D.

When the participants who had passed the qualifying examination were asked about their experience of it, the overwhelming majority stated that it was 'stressful' and were relieved to have it out of the way. Adjectives such as 'brutal', 'terrifying', 'difficult' and 'hard' also featured. Retrospectively, many felt they had not performed as well as they expected. The following quote is characteristic of a large number of responses elicited from participants:

"I think probably I spent like two months preparing. Well, I guess it does force you to go over all the material...I just know it was a very stressful experience. It didn't go as smoothly as I thought it would" (male, international doctoral student: 4). 


\section{Section 2: Integration Mechanisms}

\section{Type of financial support}

Students were supported financially by a variety of sources. Most notably, over half of the participants were funded by the department initially before being appointed to the position of graduate student instructor (GSI). Seven graduates were funded through fellowships, four of whom boasted international status. One woman graduate stated that she received a fellowship due to her 'minority' status. Without exception, those funded by this latter source viewed their position as fortunate in terms of being able to concentrate wholly on their studies, many having the option to teach should they desire.

Many interviewees commented that their GSI peers taught to the detriment of their graduate program in terms of large amounts of time allocated to teaching. This resonates with other evidence that indicates that shorter time-to-completion is associated with fellowship funding (Tuckman, Coyle, \& Bae, 1990), although contests research conducted by Sheridan and Pyke (1994) suggesting that fellowship recipients take longer to complete their studies compared to research or teaching assistants. The following excerpts elicited from funded graduates are characteristic of a large number of responses:

'I'm pleased that I've done teaching in reasonable quantity as it's an enjoyable and useful experience. But I'm pleased that I haven't had to do too much" (male, domestic doctoral student: 1).

"[The fellowship] has really allowed me a lot of extra time to work. I see my friends teaching and see how much time it takes. It's really very, very nice. I don't do any paid work" (male, domestic doctoral student: 7).

Although some research suggests that students with teaching assistantships, as opposed to students receiving fellowships, are less likely to complete their Ph.D.s (in Economics, English, Mathematics and Physics) (Ehrenberg \& Mavros 1995), Lovitts (2001) suggests that fullfellowship recipients are at risk of non-completion due to limited contact with peers and a lack of office space. Despite this, and irrespective of source of funding, the majority of participants interviewed were on campus fairly frequently and all access to office space which they shared with peers.

\section{Teaching opportunities}

With the exception of one participant who bragged that he did not spend very much time on teaching, the remaining GSIs spent anything between eight hours to twenty hours a week on preparation, grading, teaching and office hours with the mode number of weekly hours allocated to teaching totaling ten. Three participants claimed that teaching interfered with their Ph.D. and held the view that it was not part of the Ph.D. experience.

"I'm not hugely enthusiastic as it's not really what I'm here for. But it's something I feel I do an acceptable job at" (male, domestic doctoral student: 9).

"It does get in the way of the Ph.D.. I would much prefer to have a fellowship as you finish quicker" (male, international doctoral student: 5).

In comparison, four participants viewed teaching as a 'calling' and saw it very much of the whole Ph.D. process.

"I want to become a Professor for the teaching aspect and not the research" (male, domestic doctoral student: 4).

"I hope to teach for the rest of my life" (male, international doctoral student: 1). 
"[Teaching] is great. It's something I want to do in the future" (male, domestic doctoral student: $10)$.

Typical was the following excerpt from an international student detailing the contradictory nature of teaching. On one hand it was viewed by a number of students as aiding department integration by providing a useful and rewarding experience that provided contact with members of faculty that might otherwise be absent. This resonates with other research that suggests that the assistantship in the form of research or teaching plays a fundamental role in social and academic integration (Ethington \& Pisani, 1993; Lovitts \& Nelson, 2000). Coupled with the positive aspect, however, was the sense that teaching diluted the Ph.D. experience as it took time away from graduates' own studies.

"[Teaching] is in some sense an obstacle as there are a lot of times when the research is going well and I would like to have more time to work on it but I have to stop because I have office hours or I have to teach a class. But I am really involved in teaching and I want to do the best possible job. But a lot of times I get tired -4 or 5 hours with students is a long time. It's a mixed attitude that I have. When I was a GSI I kind of liked the experience of teaching and missed it when I wasn't" (male, international doctoral student: 1).

"I like teaching. I like to teach people how beautiful mathematics is. But it is exhausting" (male, international doctoral student: 6).

Only a small minority of students, however, felt that teaching was compatible with their own studies, despite the relatively large number of hours dedicated to it:

"I don't think it [teaching] affected my research even though it occupied a lot of my time" (male, international doctoral student: 4).

Among these participants there was the notion that teaching was good for time management since they were forced to come into the department which served to improve their work ethic. In addition, teaching provided an alternative pursuit that was still math-related.

"When you teach it's 10-15 hours a week so it's hard to have time for research. But it is nice to have something to do that's different. It's mathematics but a different kind of mathematics so it's a different kind of keeping yourself occupied. I need that" (male, international doctoral student:

5)

One theme that emerged from the interview data was that of responsibility and, interestingly, this was voiced by two female participants.

"There are some aspects of teaching that I enjoy. I don't enjoy the grading, the paperwork, the official aspect of it and I don't enjoy the responsibility of being such an essential part of the students' learning experience" (female, domestic doctoral student: 3 ).

"This is my first semester [of teaching] and it's a little strange. I feel responsible for them" (female, domestic doctoral student: 4).

The above excerpts are interesting in the light of research conducted by Hollenshead, Younce \& Wenzel (1994). They found that concern was voiced by graduates over the quality of teaching received by undergraduates due to excessive workloads and responsibilities.

\section{Advisor-advisee relationship}

Of those fifteen doctoral students working under the supervision of an advisor, the vast majority felt that selecting an advisor was a relatively straightforward process. The reason for the ease with which most participants made their choice was twofold. Firstly, six graduates stated that they ap- 
proached professors whose classes they had most enjoyed in the first year and whom they felt were 'nice'.

"I did it arbitrarily so it was almost too easy. He taught me in the first year and I liked his manner, it made sense. I went to talk to him and he didn't have too many students so he was happy to take me on" (male, domestic doctoral student: 3 ).

"I took a class in my first year and it was taught by my advisor and it was so much more interesting than other stuff I'd done and when I talked to him, he was really nice" (female, domestic doctoral student: 2).

In addition, a substantial number of participants stated that their mathematical interests limited their choice significantly.

"It was easy the selection as I knew I wanted number theory. The people who are working in number theory... well, some people I did not want to work with, some people were not available but there was one professor who I wanted to work with and he was nice to me. He was an easy decision. I work with him and another professor now" (male, international doctoral student: 1).

Only one participant commented on the long process of selecting an advisor.

"I was starting to get worried. I think I took longer than most people in my class. There's a lot of competition for advisors and I spent most of my first year... well, I didn't know what I wanted to do and then in my second year I actively was trying to find someone. It took me a long time to realize what I wanted to do and who would be good to work with. And then who would take me" (male, domestic doctoral student: 7).

Two female students stated that they were anxious about approaching a prospective advisor. This differs somewhat from those who viewed the qualifying examination as useful in terms of facilitating the advisor selection process. For a couple of doctoral students, however, the thought of approaching a professor was extremely intimidating to the extent that it might impede doctoral persistence:

"I'm very, very, very nervous about the prospect of talking to a professor [to act as an advisor]. Like, I'm terrified. So I've thought that I may not get through this because of that. Sometimes, I worry that I don't like it enough, that I'm not good enough. I guess I think other people are much better" (female, domestic doctoral student: 4).

The overwhelming majority of students met with their advisor on a weekly basis to discuss their research and a number of these students spoke in favorable terms about their advisor. Typical was the following excerpt:

"I am a very lucky person as my advisor gives me a lot of feedback, a lot of personal care and a lot of dedication but that's not the case for all" (male, international doctoral student: 5).

Whilst three participants had switched their advisors, two doctoral students claimed their advisors were inaccessible. This is a cause for concern given that research suggests that poor advisorstudent relationship impede doctoral persistence (Nerad \& Sands Miller, 1996). Moreover, evidence shows that the most primary factor in students' decision-making process regarding doctoral withdrawal or persistence is the relationship with an advisor; 'Students who complete their degrees are fully twice as likely to express satisfaction with their faculty advisors as are students who leave' (Lovitts \& Nelson, 2000, p. 50).

"He is a strange person. He has an office hour for undergraduates and I have to try and seem him then as he is loathed to make an appointment with me. I guess he has more important things on. So I don't really see him as much as I would like. There were several times when I had questions that were stopping me from proceeding and he wasn't around to help me or I'd think that I'd 
come up with a solution to a problem and I hadn't. I now email, it's crossed my mind that I should get a new advisor so I've been testing the waters this semester" (male, domestic doctoral student: 3 ).

A good choice of advisor was viewed as fundamental by the majority of participants since doctoral completion was facilitated by advisor support, input and encouragement. If an advisor placed the onus entirely on the student, time-to-completion was lengthened. In addition, if a student switched advisors, or had difficulty selecting one initially, persistence was impeded.

"My advisor's students...well, the last few have graduated in 3 years, 4 years. You know, so he churns them out. The secret for the 3 year people is they're smart. But my advisor takes people often from the instant they arrive in Berkeley and starts working with them. He makes sure they have projects going on and that some on them turn into papers and once you have enough papers you can graduate. There are definitely advisors who say, 'well, you should go and figure out your own problem' and that can be a six month time when you're messing around" (male, domestic doctoral student: 7).

"Different advisors have different philosophies on advising. So I think that when you're looking for an advisor it's helpful to choose someone who will help you find a problem, will make sure the problem leads somewhere and will be able to suggest approaches" (female, domestic doctoral student: 1).

Closely related to advisor-advisee relationship is the dissertation experience. Over half of the doctoral students interviewed stated that difficulty in selecting a research topic or a change in direction of a research topic hindered doctoral persistence: 'I think it's maybe just not being sure what they want to do. It takes a while' (male, domestic doctoral student: 10).

Of those who had started working on a research problem, three students interviewed had switched their dissertation titles due to a lack of progress. All were philosophical about the change in focus despite it increasing their time-to-completion.

"Originally the dissertation that I was working on was essentially one that my advisor came up with and recently the fact that I wasn't making a great deal of progress on that, and at the same time, something that started as a side project with another professor on something that was completely unrelated, I found myself making considerably more progress on that. So just in the past month I decided to switch advisors. It was a difficult decision and I spent at least a couple of months making that decision. Unlike my old topic, I enjoy it a great deal and it's really my research as I have more control over the direction it goes. The problem with the old topic is that it was a vague and difficult topic so not a great deal was known about it. I think there is some degree of chance involved in terms of whether the problem was feasible. The uncertainty of whether it could be solved was not good" (male, domestic doctoral student: 1).

Inherent in the previous excerpt are two themes that warrant further examination. The first is ownership of the thesis. Many participants, like the interviewee here, commented on the fact that their advisor had a great deal of input in relation to the direction of the research, making their role somewhat redundant.

"My advisor sends me a couple of emails a week with different problems and puts papers in my mailbox so there's no period when we sat down and thought 'hey, what I am going to work on?'. It's more a period with me being thrown different things that I could work on and eventually some of those became real projects. And every few months I talk to him and he says, 'right, this is the direction your dissertation is going to go' and 'this may be a rough title' but it changes bit by bit as he keeps thinking of new ideas and I keep hopefully solving problems" (male, domestic doctoral student: 7). 
In contrast, there were three cases reported whereby the onus of the doctorate direction was very much on the student and that was something enjoyed by the students.

"I've been researching possible research areas...I try to keep an open mind and read as much as possible but I am narrowing myself down. I expect to be here at least another year but probably more like two years as I don't have a clear idea what topic I want to research which means I've got to keep reading until something really strikes my imagination and from there I have to select a problem that is do-able and I can write-up" (male, domestic doctoral student: 3 ).

It was evident from the interview data that in four cases research problems received input from both advisors and students themselves.

"My advisor gave me a couple of problems and then I choose one of them. We then decided that that should be the title of my dissertation. So it was a very, very vague title and we didn't even know if it would work out or not. I had to ask him for the problems so he didn't push me in that direction" (male, domestic doctoral student: 6).

Interestingly, six interviewees alleged that 'luck' played a key role in determining how quickly a student progressed through his or her dissertation.

"I think part of it is just luck. Doing research is kind of like being blindfolded. You have an unsolved question and you don't know how to solve it. There are so many ways to think about something and so few of them will lead to the correct answer. So it's kind of a question of stumbling across them" (female, domestic doctoral student: 1).

"I think I was very lucky. Very lucky to get this problem which was not easy but I've found an easy way out. If I hadn't found a good problem and made good progress, well, I don't know" (male, domestic doctoral student: 6).

A number of interviewees stated that the aspiration for a dissertation be ground-breaking could hinder the process somewhat. As illustrative in the first excerpt below, some students were unwilling to graduate despite that fact that they were, in theory, in a position to. Nerad \& Cerny (1993) suggest that the definition of a dissertation is a factor in time-to-degree and attrition. Whilst the sciences and engineering often view the dissertation as a test of future ability to do research, the humanities and social sciences regard the dissertation as a major contribution to the field, a view which the student in the following excerpt adheres.

"Actually, I'm done with my dissertation. If I want to graduate, I can graduate in the summer. But the problem is...well, I like what I have put in my dissertation but the problem is, well, there's a gap between my expectations for myself. My ambition was when I came to Berkeley was that I would get a remarkable result and I would become very well known but the problem, it is an interesting result but it is not remarkable and I feel disappointed for myself. It's okay. So that's why I want to stay one more year. This is my fourth year. My advisor thinks I should graduate. He thinks it's enough. I do like him very much and he does encourage me to graduate but sometimes I lack confidence for myself and sometimes I just, well, my maturity academically is not that well developed so I just want to stay on. I can learn more things and psychologically it's good" (male, international doctoral student: 6).

"The other thing is that people have this idea that a thesis is going to be ground breaking and it's going to set off bells and gongs in the mathematics community and so they might pass up a thing or two that could be a thesis" (female, domestic doctoral student: 1). 


\section{Discussion}

Nearly half the participants interviewed did not pass the preliminary examination on their first attempt. For those who passed on their third attempt or who were about to sit the examination a third time, the associated stress was very high. The majority of doctoral students viewed the preliminary examination as difficult requiring a great deal of preparation but many claimed that passing boosted confidence levels in mathematical ability. Three quarters of those interviewed had passed their qualifying examination and a substantial number of interviewees understood the rationale underpinning the examination. Not unlike the aforementioned examination, many found the experience stressful and difficult and even brutal and terrifying with many stating that, retrospectively, they had not performed as well as expected. Ph.D. requirements were viewed by the majority of students as hurdles surmounted and, as such, the preliminary and qualifying examinations facilitated doctoral persistence by providing an endorsement of graduate study.

Without exception, fellowship recipients viewed their position as fortunate in terms of being able to concentrate wholly on their studies, many having the option to teach should they desire and, as such, this type of financial support was seen as facilitating doctoral persistence. Graduate student instructors often viewed their position as two-fold; whilst teaching aided department integration by providing a useful and rewarding experience that provided contact with members of faculty that might otherwise be absent, teaching also diluted the Ph.D. experience taking time away from graduates' own studies and, consequently, impeded doctoral persistence to a certain extent.

Student-advisor contact for the majority of students was frequent and many interviewees spoke about their advisors in favorable terms. Only a handful of students claimed poor advisor relations and, consequently, switched thus hampering their doctoral study. A good choice of advisor was viewed as fundamental by the majority of students since doctoral persistence was facilitated by advisor encouragement and support. Over half of the doctoral students interviewed stated that difficulty in selecting a research topic or a change in direction of a research topic hindered doctoral persistence and a number alleged that 'luck' played a key role in determining how quickly a student progressed through his or her dissertation. The aspiration for a dissertation be groundbreaking was said to hinder the doctoral process somewhat.

Given that a good advisor-advisee relationship is a primary reason for doctoral persistence, it warrants further consideration. What does a "good choice of advisor" actually mean? From the interview material, it was evident that accessibility to one's graduate advisor is fundamental and, in addition, a student needs to feel that he/she is able to approach their advisor. Narrowing this down further, however, to a set of general characteristics is difficult. What works for one student may not work for another, and vice versa, although having a supportive infrastructure in place can only serve to improve the Ph.D. experience.

The interview findings illustrated that doctoral persistence rests on student ownership of the thesis and, in addition, sufficient input from the advisor. Implicit in the concept of 'student ownership of the thesis' is the extent to which a student may feel ownership. Is it enough for the doctoral student to come up with the idea/title of the thesis to have ownership? If subsequent work on the thesis requires a great deal of advisor direction and input, does student ownership waver? If the advisor initially selects the problem area, does the student retain ownership? Such scenarios have serious implications; in the former, a student may feel ownership of their thesis but the problem identified may not be feasible which can ultimately extend time-to-completion. In the latter, $\mathrm{s} /$ he may feel alienated from the Ph.D. process (which may undermine progress), despite an expected shorter time-to-completion. It could be argued, speculatively, that much is dependent on personality-type. A student may rise to the challenge of selecting a dissertation title/problem and thrive within that scholarly environment whereas another student may require substantial advisor direction and input. Moreover, related to the concept of 'student ownership of the thesis' is the 
question of what is rewarded in the doctorate? Given that Mathematics is the selected disciplinary area of interest in this paper, what is rewarded must vary by sub-specialty. In some subspecialties, it could be argued that requirements of the Ph.D. include, among other factors, independent thought and creativity and here ownership of the thesis lies with the student. In other cases where ownership is less clear, it may be diligence and hard work that are the coin of the realm.

A degree of caution must, however, be taken in the light of these findings. The research was small scale comprising interview data elicited from twenty interviews with mathematics doctoral students. In addition, the focus was on 'persisters' which omitted a whole host of other students including those who have withdrawn from their doctoral studies. Furthermore, although the emphasis in this study is mathematics, comparisons with other disciplines may produce interesting findings as to the relationship between discipline, doctoral persistence and academic integration. The results are, therefore, very specific to the cohort under study.

\section{References}

Abedi, J., \& Benkin, E. (1987). The effects of students' academic, financial, and demographic variables on time to the doctorate. Research in Higher Education, 27, 3-14.

American Mathematical Society [AMS]. (2003). Excerpts from the 2002 first report, Annual survey of the mathematical sciences report on the 2001-2002 new doctoral recipients. Retrieved March 2004, from http://www.ams.org/employment/02Survey.DG.pdf

Baird, L. (1993). Using research and theoretical models of graduate student progress. In L. Baird (Ed.), Increasing graduate student retention and degree attainment (pp.3-12). San Francisco: Jossey-Bass Publishers.

Berg, H.M. \& Ferber, M.A. (1983). Men and women graduate students: Who succeeds and why? Journal of Higher Education, 54(6): 629-648.

Bowen, W.G. \& Rudenstine, N.L. (1992). In pursuit of the Ph.D. Princeton, New Jersey: Princeton University Press.

Ehrenberg, R.G. \& Mavros, P.G. (1995). Do doctoral students' financial support patterns affect their timesto-degree and completion probabilities? Journal of Human Resources, 30, 581-609.

Ethington, C.A. \& Pisani, A. (1993). The RA and TA experience: Impediments and benefits to graduate study. Research in Higher Education, 34 (3), 343-354.

Golde, C.M.. (2000). Should I stay or should I go. Review of Higher Education, 23 (2), 199-227.

Herzig, A.H. (2002). Where have all the doctoral students gone? Participation of doctoral students in authentic mathematical activity as a necessary condition for persistence toward the Ph.D. Educational Studies in Mathematics, 50, 177-212.

Linn, M.C. \& Kessel, C. (1996). Success in mathematics: Increasing talent and gender diversity among college majors. CBMS Issues in Mathematical Education, 6, 101-144.

Lovitts, B.E. (2001). Leaving the ivory tower: The causes and consequences of departure from doctoral study. Maryland: Rowman \& Littlefield Publishers.

Lovitts, B.E. \& Nelson, C. (2000). The hidden crisis in graduate education. Attrition from Ph.D. programs. Academe, 6, Nov/Dec, 44-50.

MLA Committee on Professional Development. (1998). A guide to evaluating the mission, size, and composition of your doctoral programs. ADE Bulletin, 119, 46-49.

Nerad, M \& Cerny, J. (1993). From facts to action: Expanding the graduate division's educational role. In L. Baird (Ed.), Increasing graduate student retention and degree attainment. (pp. 27-39). San Francisco: Jossey-Bass Publishers. 
Nerad, M \& Sands Miller, D. (1996). Increasing student retention in graduate and professional programs. New Directions of Institutional Research, 92, 61-76.

Pyke, S.W. (1997). Education and the "Woman Question". Canadian Psychology, 38(3), 154-163.

Pyke, S.W. \& Sheridan, P.M. (1993). Logistic regression analysis of graduate student retention. Canadian Journal of Higher Education, XXIII (2), 44-64.

Stage, F.K. \& Maple, S.A. (1996). Incompatible goals: Narratives of graduate women in the mathematics pipeline. American Educational Research Journal, 33(1), 23-51.

Tinto, V. (1987) Leaving college: Rethinking the causes and cures of student attrition. Chicago: The University of Chicago Press.

Tuckman, H.P., Coyle, S., \& Bae, Y. (1990). On time to the doctorate. Washington DC: National Academy Press.

UC Berkeley Mathematics Website. (2004). Retrieved March 2004, from http://math.berkeley.edu/

\section{Biography}

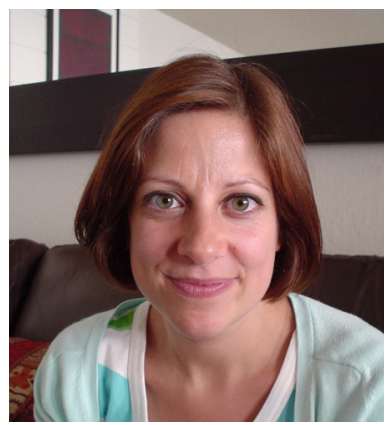

Dr. Sarah Earl-Novell earned her Ph.D. in Sociology from the University of Sussex, U.K. before embarking on postdoctoral work at the Center for Studies in Higher Education, University of California, Berkeley. Her research interests include gender differences in academic achievement at degree level and doctoral attrition. She is currently a postdoctoral researcher at UC Berkeley working on a project examining scholarly communication, academic values and sustainable models. 